\title{
Barriers impeding serologic screening for celiac disease in clinically high-prevalence populations
}

\author{
Erika M Barbero', Shawna L McNally ${ }^{1,2}$, Michael C Donohue ${ }^{3}$ and Martin F Kagnoff ${ }^{1,4^{*}}$
}

\begin{abstract}
Background: Celiac disease is present in $\sim 1 \%$ of the general population in the United States and Europe. Despite the availability of inexpensive serologic screening tests, $\sim 85 \%$ of individuals with celiac disease remain undiagnosed and there is an average delay in diagnosis of symptomatic individuals with celiac disease that ranges from $\sim 5.8-11$ years. This delay is often attributed to the use of a case-based approach for detection rather than general population screening for celiac disease, and deficiencies at the level of health care professionals. This study aimed to assess if patient-centered barriers have a role in impeding serologic screening for celiac disease in individuals from populations that are clinically at an increased risk for celiac disease.
\end{abstract}

Methods: 119 adults meeting study inclusion criteria for being at a higher risk for celiac disease were recruited from the general population. Participants completed a survey/questionnaire at the William K. Warren Medical Research Center for Celiac Disease that addressed demographic information, celiac disease related symptoms (gastrointestinal and extraintestinal), family history, co-morbid diseases and conditions associated with celiac disease, and patient-centered barriers to screening for celiac disease. All participants underwent serologic screening for celiac disease using the IgA tissue transglutaminase antibody (IgA tTG) and, if positive, testing for IgA anti-endomysial antibody (IgA EMA) as a confirmatory test.

Results: Two barriers to serologic testing were significant across the participant pool. These were participants not knowing they were at risk for celiac disease before learning of the study, and participants not knowing where to get tested for celiac disease. Among participants with incomes less than \$25,000/year and those less than the median age, not having a doctor to order the test was a significant barrier, and this strongly correlated with not having health insurance. Symptoms and co-morbid conditions were similar among those whose IgA tTG were negative and those who tested positive.

Conclusion: There are significant patient-centered barriers that impede serologic screening and contribute to the delayed detection and diagnosis of celiac disease. These barriers may be lessened by greater education of the public and health care professionals about celiac disease symptoms, risk factors, and serologic testing.

Keywords: Celiac disease, Serologic screening, Barriers to screening

\footnotetext{
* Correspondence: mkagnoff@ucsd.edu

'Department of Medicine, Division of Gastroenterology, University of

California San Diego, 9500 Gilman Drive, La Jolla, CA 92093 MC 0623D, USA

${ }^{4}$ Department of Pediatrics, Division of Gastroenterology, University of

California San Diego, La Jolla, CA, USA

Full list of author information is available at the end of the article
} 


\section{Background}

Celiac disease is characterized by small intestinal mucosal damage and nutrient malabsorption. Disease is activated in genetically susceptible individuals by dietary exposure to gluten, the term commonly used for nitrogen-rich storage proteins found in wheat, barley, and rye.

Celiac disease affects approximately $1 \%$ of the population in the U.S. (i.e. 2.3 million) whereas its prevalence in the countries in Europe varies from $\sim 0.3 \%$ in Germany to $\sim 2.4 \%$ in Finland [1]. Celiac disease is common in parts of North Africa and areas of the Middle East [2], but it is rare in the Japanese population consistent with a marked underrepresentation of the major human leukocyte antigen (HLA) DQ alleles that are required for disease susceptibility [3-5].

Celiac disease can present with gastrointestinal tract symptoms, a wide array of extraintestinal manifestations, or both [6]. Gastrointestinal symptoms frequently include increased gas and bloating, abdominal pain, chronic diarrhea or constipation, and weight loss, whereas extraintestinal manifestations frequently include iron deficiency with or without anemia, an unexplained decrease in bone density or premature onset osteoporosis, unexplained increases in liver transaminases, depression, chronic fatigue, peripheral neuropathy, aphthous stomatitis, unexplained infertility, and dental enamel defects.

Individuals with a high risk for celiac disease include first-degree, and to a lesser extent second degree, relatives of patients with celiac disease [7,8]. In addition, individuals with co-morbid diseases such as type I diabetes mellitus, autoimmune thyroid disease, dermatitis herpetiformis, Sjogren's disease, microscopic colitis, and autoimmune liver disease have an increased prevalence of celiac disease $[8,9]$. Celiac disease has also been reported to be increased in those with dental enamel hypoplasia [10], cerebellar ataxia [11], and migraine headaches [12], and in a subset of individuals with irritable bowel syndrome, although the latter has been controversial [13].

Current guidelines recommend screening for celiac disease by assaying for serum IgA antibodies to the enzyme tissue transglutaminase 2 (IgA tTG) $[14,15]$. The IgA antiendomysial antibody (EMA) test often is used as a follow up confirmatory test [8]. Esophagogastroduodenoscopy with small intestinal mucosal biopsy is the current gold standard for diagnosis in adults, although recent guidelines from the European Society of Pediatric Gastroenterology, Hepatology, and Nutrition endorse the diagnosis of celiac disease in some children in the absence of small intestinal mucosal biopsy [16].

Case finding in adults at high risk for celiac disease using serologic tests was recommended by a National Institutes of Health (NIH) Consensus Conference on Celiac Disease, the American Gastroenterology Association (AGA), and by the American College of Gastroenterology (ACG)
$[15,17,18]$. In symptomatic patients with celiac disease, early diagnosis and treatment with a strict gluten free diet alleviates most symptoms, decreases morbidity and mortality, and is associated with an improved quality of life [19-21]. It is less clear if there is an improvement in quality of life and a mortality benefit to early diagnosis and treatment of screening detected asymptomatic individuals with celiac disease $[9,22,23]$.

Epidemiologic studies estimate that the prevalence of celiac disease may have increased by as much as fourfold since 1954 [23]. Moreover, as many as $85 \%$ of individuals with celiac disease have not been detected and diagnosed [24]. Among diagnosed celiac disease patients, the average time from symptom onset to diagnosis has ranged from 5.8 to 11 years despite the availability of sensitive and specific serologic screening tests [19,20,25]. Further, patients may carry erroneous diagnoses during those years until a correct diagnosis is made. In addition to morbidities associated with undiagnosed symptomatic patients, those with undiagnosed celiac disease were reported to have a higher mortality rate than those with negative serology for celiac disease $[23,26]$.

Reasons for the marked under-diagnosis of celiac disease among individuals in the general population who are clinically at an increased risk for celiac disease have not been explored. Patients that have been diagnosed with celiac disease often cite perceived deficiencies in the health care system. These include, for example, a lack of physician and health care provider awareness of the wide array of symptoms and presentations of celiac disease, its association with other diseases, and current serologic screening options [27]. We hypothesized that patient-centered barriers to screening for celiac disease also play an important role in the under-detection and -diagnosis of celiac disease. We report herein on patientcentered barriers to antibody based screening for celiac disease among clinically high-risk individuals recruited from the general population.

\section{Methods}

\section{Recruitment and selection of the study population}

Potential study participants were recruited through flyers posted in local supermarkets, community health clinics, community centers, on the University of California, San Diego (UCSD) college campus, and on local celiac disease websites (see flyer, Additional file 1). The flyer indicated researchers at the William K. Warren Medical Research Center for Celiac Disease at UCSD were "seeking individuals who may have celiac disease to participate in a research study to investigate reasons for poor diagnosis rates among individuals who are at high risk for celiac disease". Individuals over age 18 wanting more information and to see if they qualified for participation in the study were instructed to download an application 
from the web and/or to contact with the Warren Medical Research Center for Celiac Disease Clinical Studies Office via the web or telephone. Respondents were informed that the study involved providing a serum sample and completing a study questionnaire at UCSD. Those interested in participating in the study were provided a brief written application (Additional file 2) and following its submission underwent a standardized telephone screen by the clinical study coordinator to ascertain that they met study inclusion criteria or had exclusion criteria (see Additional file 3). Inclusion criteria required the applicant to have at least one qualifying risk factor for celiac disease and at least one potential barrier to diagnosis (see list of qualifying risk factors and potential barriers to diagnosis in Lists 1 and 2, respectively, below). Criteria for determining if individuals were at high risk for celiac disease were developed according to AGA guidelines [15]. Individuals were excluded if they had been screened with a "blood test" for celiac disease in the past five years, had excluded gluten from the diet within the past month, or if a 24 hour diet history indicated they were consuming minimal gluten in the diet. Individuals reporting they had been tested with a fecal, skin or sputum test for celiac disease were not excluded since such tests have not been validated for celiac disease screening. The research team made a final decision for inclusion or exclusion of each applicant after review of the written application and telephone interview information.

\author{
List 1 Qualifying risk factors \\ Gastrointestinal risk factors ( $>4$ weeks and \\ impairing quality of life) \\ Chronic diarrhea \\ Recurrent abdominal pain \\ Irritable bowel syndrome (diagnosed) \\ Bloating \\ Non-gastrointestinal risk factors \\ Autoimmune thyroid disease \\ Osteoporosis or bone disease diagnosed under age 50 \\ Unexplained infertility \\ Sjogren's syndrome \\ Dermatitis herpetiformis \\ Liver disease (autoimmune, primary biliary cirrhosis, or \\ unexplained cause for abnormal liver tests) \\ Type 1 diabetes mellitus \\ Anemia not responsive to iron therapy \\ Other \\ Family history of celiac disease $\left(1^{\text {st }}\right.$ or $2^{\text {nd }}$ degree relative)
}

\section{List 2 Qualifying potential barriers to diagnosis}

I did not know where to be tested

I did not know about celiac disease before learning about the study
I did not know I was at risk for celiac disease before learning about the study

I do not have a physician

I was not been motivated to be tested until recently

My doctor does not know which test to order

I don't have insurance

My doctor will not test me

I did not want to see a doctor to be tested

I do not want my insurance company to know the results

I did not have symptoms so I did not want to be tested

I can't afford the cost or co-payment

I have been scared to be tested until recently

I was tested for celiac disease with a skin/fecal/saliva

test and did not know I should get a blood test

I cannot take time off work to be tested

One hundred nineteen applicants met inclusion criteria ( $84 \%$ of telephone screened individuals) and 22 applicants (16\%) were excluded according to the study exclusion criteria after the telephone interview. All 119 applicants accepted into the study kept their scheduled appointments for serologic testing and completed a self-administered study survey (Additional file 4) at the UCSD Clinical Research Center.

Members of the William K. Warren Medical Research Center at UCSD designed the study protocol. Questions for an initial pilot study questionnaire were developed by the authors with additional input from a volunteer focus group provided from the membership of the local San Diego chapter of the Celiac Support Association (CSA), the Celiac Disease Foundation (CDF), and members of the Warren Center Community Advisory Board. The latter groups suggested the addition and/or deletion of questions, and the rewording of questions based, in large measure, on what these individuals viewed from personal experience as barriers that occurred during the process of obtaining the diagnoses of celiac disease. An initial pilot study carried out by the Warren Center (S. McNally and M.F. Kagnoff, unpublished data) revealed areas for improvement in the study design, information sought in the telephone interview process, and clarity of the finally adopted questionnaire. No participants in the pilot study were included in the present study. The final questionnaire provided the option for participants to add other barriers they experienced that were not listed in the questionnaire. The UCSD Institutional Review Board approved these investigations.

\section{Serologic tests}

Each participant donated a blood sample drawn at UCSD that was assayed for IgA tTG levels by enzyme-linked immunosorbent assay at Prometheus Laboratories, San Diego, California, and samples testing positive were 
further assayed for IgA EMA. Total IgA levels were not measured, per current clinical guidelines, as IgA deficiency has not been deemed common enough to warrant routine testing unless there is otherwise reason to suspect it [8]. Participants were notified of serologic test results and interpretation of the results by mail in accordance with requirements and approval of the UCSD Institutional Review Board. All subjects were encouraged to consult a physician regarding their symptoms and the test results.

\section{Statistical analysis}

Statistical analysis of the barriers to screening was performed across the total participant group and components of the demographic subgroups using the Wilcoxon Rank Sum Test. Specifically, the five point Likert-scale responses were submitted to the Wilcoxon Rank Sum Test with one-sided alternative hypothesis median $\mu>3$ ("agree" or "strongly agree"). Fisher's Exact Test was used to assess the strength of the association between each barrier and demographic categories (i.e., sex, level of education, and income). $P$-values $\leq 0.05$ were considered significant. Spearman's rank correlation coefficient was used to assess the correlation between each barrier. Bias-corrected and accelerated bootstrap with 1000 replicates was used to estimate $95 \%$ confidence intervals for Spearman's rank correlation [28].

\section{Results}

Demographics of the study population are shown in Table 1. The mean and median age of participants was 40.9 (range 19-78) and 34.9 years respectively, with a $3: 1$ female to male ratio that approximates the female sex predominance in celiac disease diagnosed in adult populations $[12,19,29,30]$. There was no significant difference in income or education level or ethnicity between female and male participants. Annual income of participants ranged from less than $\$ 25,000$ USD to greater than $\$ 100,000$ USD. Approximately $2 / 3^{\text {rds }}$ of participants were employed outside the home, $8 \%$ were students and $7 \%$ were retired. A majority of participants self-identified as White/non-Hispanic (79\%) or Hispanic (13.4\%). The remaining participants were Asian (3), Black (3), Arab/Middle Eastern (2), or Indian (1). Thirtythree participants reported having a first-degree family member with celiac disease, 18 of which were reported to be biopsy-proven. The majority of participants learned of the study from seeing the flyer in a grocery store, on the internet, or from friends or family members who saw the flyer. Interestingly, none of the patients reported learning of the study from flyers posted at community health clinics.

Participant reported gastrointestinal and extraintestinal symptoms/findings on the survey are shown in
Table 1 Summary of demographics

\begin{tabular}{ll}
\hline Age & \\
Mean & 40.9 \\
Range & $19-78$ \\
Standard deviation & 15.1 \\
Sex & \\
Males & $28(23 \%)$ \\
Females & $91(77 \%)$ \\
Income (USD) & \\
$<\$ 25,000$ & $36(31 \%)$ \\
\$25,000-\$50,000 & $33(28 \%)$ \\
\$50,000-\$100,000 & $31(27 \%)$ \\
$>$ \$100,000 & $16(14 \%)$ \\
Education & \\
High School/GED & $11(9 \%)$ \\
Some college & $35(30 \%)$ \\
4 year degree & $37(31 \%)$ \\
Graduate degree & $35(30 \%)$ \\
Employment & \\
Employed & $77(65 \%)$ \\
Unemployed & \\
Race/Ethnicity & $41(35 \%)$ \\
Hispanic & \\
White non Hispanic & $16(13.4 \%)$ \\
Other & $94(79 \%)$ \\
\hline
\end{tabular}

"Includes unemployed able to work, unemployed not able to work, retirees, homemakers, students, and non-paid volunteers.

Table 2. The spectrum of symptoms closely resembled that reported by patients with documented celiac disease patients prior to diagnosis [12], and in the majority of participants the reported symptoms were present for more than six months. The most common gastrointestinal symptoms were gas and bloating, abdominal cramping or pain, diarrhea or constipation, nausea, and mouth sores. More than $1 / 3^{\text {rd }}$ of participants reported extraintestinal symptoms that included fatigue, muscle cramps or pain, joint pain, numbness or tingling in the fingers or toes (i.e. paresthesias), symptoms of depression or anxiety, recurring headaches or migraines, pruritic skin rashes, and bone pain. The most frequently cited co-morbid health problems were depression, irritable bowel syndrome, iron-deficiency anemia and autoimmune thyroid disease (Table 3). Subjectively, most participants regarded their health as good to excellent (7\% excellent, 34\% very good, $44 \%$ good, $12 \%$ fair, and $3 \%$ poor).

Two barriers were statistically significant for the population studied: "I did not know where to get tested", and "I did not know I was at risk for celiac disease" (Table 4). Further, more than $1 / 3^{\text {rd }}$ of participants either strongly 
Table 2 Frequency of symptoms

\begin{tabular}{ll}
\hline Symptom & N (\%) \\
\hline${ }^{*}$ Gas and bloating & $103(87.3)$ \\
${ }^{*}$ Abdominal pain or cramping & $93(79.5)$ \\
Fatigue & $93(78.8)$ \\
${ }^{*}$ Diarrhea & $76(65.0)$ \\
Constipation & $72(62.1)$ \\
Muscle cramps/pain & $71(60.2)$ \\
Joint pain & $68(57.6)$ \\
Numbness or tingling in fingers or toes & $62(52.5)$ \\
Symptoms of depression & $58(49.6)$ \\
Anxiety & $57(48.3)$ \\
Recurring headaches or migraines & $56(47.9)$ \\
Nausea & $50(42.7)$ \\
Itchy skin rash & $49(41.9)$ \\
Mouth sores & $40(33.9)$ \\
Bone pain & $39(33.1)$ \\
Poor dental enamel formation & $26(22.2)$ \\
Weight loss (unintentional) & $20(17.1)$ \\
Vomiting & $13(11.1)$ \\
Infertility & $12(10.3)$ \\
Translucent-looking teeth & $11(9.5)$ \\
Seizures & $3(2.6)$ \\
\hline Sther & $20(16.8)$ \\
\hline
\end{tabular}

"Symptoms/signs used to qualify individuals for inclusion in the study if persisting for more than four weeks.

agreed or agreed with the statements, "I did not know where to get tested" (60.5\%), "I did not know anything about celiac disease until recently" (52.6\%), "I did not know I was at risk for celiac disease" (50.9\%), "I do not have a doctor to order the test" (47.5\%), "I was not motivated to get tested until recently" (41.7\%), "I have a doctor, but I do not think he/she knows what test to order" (35.3\%), "I knew that I may be at risk for celiac disease, but I did not know there was a screening test available" (34.7\%), and "I have no insurance coverage to take care of the costs" (33.7\%), whereas barriers which were cited by less than $10 \%$ of the participants were, "I do not want my health insurance company to know the results of the test", "I do not have any symptoms and so have not wanted to get tested", "I have insurance, but cannot afford co-payment for the test", "I have been scared to get tested until recently or did not want to know the results", "I was tested with a skin/fecal/saliva test and did not know that I should get the blood test", "I cannot take time off from work to get tested at a doctor's office", and "I was told before that I did not need to get tested because of my race or ethnicity" (Figure 1).
Table 3 Frequency of co-morbid health problems

\begin{tabular}{|c|c|}
\hline Co-morbid health problems & $\mathrm{N}(\%)$ \\
\hline Depression (diagnosed) & $37(31.1)$ \\
\hline *Irritable Bowel Syndrome (IBS) & $32(26.9)$ \\
\hline Anemia caused by iron deficiency & $25(21.0)$ \\
\hline${ }^{*}$ Autoimmune thyroid disease & $19(16.0)$ \\
\hline Anemia of unknown cause & $15(12.6)$ \\
\hline Chronic fatigue syndrome & $11(9.2)$ \\
\hline Fibromyalgia & $11(9.2)$ \\
\hline $\begin{array}{l}\text { *Bone disease, osteoporosis, or low bone } \\
\text { density before age } 50\end{array}$ & $9(7.6)$ \\
\hline${ }^{*}$ Unexplained infertility & $8(6.7)$ \\
\hline Anemia caused by B12 or folate deficiency & $7(5.9)$ \\
\hline *Sjogren's syndrome & $3(2.5)$ \\
\hline *Dermatitis herpetiformis & $2(1.7)$ \\
\hline${ }^{*}$ Autoimmune hepatitis & $1(0.8)$ \\
\hline Crohn's disease or ulcerative colitis & $1(0.8)$ \\
\hline Addison's disease & $0(0)$ \\
\hline $\begin{array}{l}\text { Anemia caused by something other than B12, } \\
\text { folate, or iron deficiency }\end{array}$ & $0(0)$ \\
\hline Cryptogenic liver disease & $0(0)$ \\
\hline $\lg$ A deficiency & $0(0)$ \\
\hline Systemic lupus erythematosus (SLE) & $0(0)$ \\
\hline *Primary biliary cirrhosis & $0(0)$ \\
\hline Primary sclerosing cholangitis & $0(0)$ \\
\hline${ }^{*}$ Type 1 insulin dependent diabetes & $0(0)$ \\
\hline *Unexplained elevated transaminase levels & $0(0)$ \\
\hline
\end{tabular}

"Health problems used to qualify individuals for participation in the study.

Several barriers were statistically significant for specific demographic groups (Table 5). In addition to not knowing where to get tested, those younger than the median age of 34.9 years were significantly more likely to not have a doctor than those older than the median age. Further, not knowing where to get tested, which was a significant barrier across the entire participant group, was highly significant among women $(p \leq 0.001, \mathrm{~N}=91)$ but not in men $(\mathrm{P}=0.314 ; \mathrm{N}=28)$.

Those with annual incomes less than $\$ 25,000$ differed from the higher income groups in that $65 \%$ indicated they did not have a doctor to order the test $(P=0.007)$, whereas the lack of a doctor to order the test was not a statistically significant barrier for the other income groups (Table 5). Consistent with that, $61.1 \%$ of individuals in the lowest income group cited the lack of health insurance as a barrier to testing $(p=0.06 ; \mathrm{N}=35)$. Not knowing where to be tested was a significant barrier for those in the lowest two income categories whereas not knowing they were at risk was a significant barrier among those in the $\$ 50,000-\$ 100,000$ annual income group. Although none of the barriers tested was statistically significant among 
Table 4 Frequency of barriers to screening

\begin{tabular}{|c|c|c|c|c|c|c|c|}
\hline Barrier statements & $\mathrm{N}$ & $S A^{1}(\%)$ & A (\%) & $\mathrm{N}(\%)$ & $\mathrm{D}(\%)$ & SD (\%) & P-value $^{2}$ \\
\hline I did not know where to get tested. & 119 & 23.5 & 37.0 & 17.7 & 9.2 & 12.6 & $<0.001$ \\
\hline I did not know I was at risk for celiac disease. & 118 & 21.2 & 29.7 & 17.8 & 17.0 & 14.4 & 0.028 \\
\hline I did not know anything about celiac disease until recently. & 118 & 21.2 & 31.4 & 11.9 & 18.6 & 17.0 & 0.075 \\
\hline I do not have a doctor to order the test. & 118 & 21.2 & 26.3 & 12.7 & 16.1 & 23.7 & 0.450 \\
\hline I was not motivated to get tested until recently. & 118 & 16.1 & 25.6 & 9.3 & 16.1 & 22.9 & 0.477 \\
\hline I have no insurance coverage to take care of the costs. & 119 & 21.9 & 11.8 & 8.4 & 22.7 & 35.3 & 0.990 \\
\hline I have a doctor, but I do not think he/she knows what test to order. & 116 & 10.3 & 25 & 19.9 & 15.5 & 29.3 & 0.995 \\
\hline $\begin{array}{l}\text { I knew that I may be at risk for celiac disease, but I did not know } \\
\text { there was a screening test available. }\end{array}$ & 118 & 11.0 & 23.7 & 17.0 & 20.3 & 28.0 & 0.995 \\
\hline I have a doctor, but he/she will not test me. & 117 & 7.7 & 13.7 & 24.8 & 23.1 & 30.8 & $>0.999$ \\
\hline I do/did not want to see a doctor for testing. & 118 & 2.5 & 13.6 & 20.3 & 30.5 & 33.1 & $>0.999$ \\
\hline $\begin{array}{l}\text { I have been scared to get tested until recently or did not want to } \\
\text { know the results. }\end{array}$ & 118 & 1.7 & 5.1 & 17.0 & 36.4 & 39.8 & $>0.999$ \\
\hline I do not have any symptoms and so have not wanted to get tested. & 119 & 0.8 & 7.6 & 14.3 & 31.9 & 45.4 & $>0.999$ \\
\hline I do not want my health insurance company to know the results of the test. & 118 & 0.8 & 7.6 & 20.3 & 18.6 & 55.1 & $>0.999$ \\
\hline I have insurance, but cannot afford co-payment for the test. & 118 & 3.4 & 3.4 & 14.4 & 24.6 & 54.2 & $>0.999$ \\
\hline $\begin{array}{l}\text { I was tested with a skin/fecal/saliva test and did not know that I should } \\
\text { get the blood test. }\end{array}$ & 117 & 0.9 & 5.1 & 13.7 & 22.2 & 58.1 & $>0.999$ \\
\hline $\begin{array}{l}\text { I was told before that I did not need to get tested because of my } \\
\text { race or ethnicity. }\end{array}$ & 118 & 0 & 1.7 & 16.1 & 27.1 & 55.1 & $>0.999$ \\
\hline I cannot take time off from work to get tested at a doctor's office. & 118 & 0 & 2.5 & 12.7 & 30.5 & 54.2 & $>0.999$ \\
\hline
\end{tabular}

${ }^{1} \mathrm{SA}=$ Strongly agree; $\mathrm{A}=$ Agree; $\mathrm{N}=$ Neither; $\mathrm{D}=$ Disagree; $\mathrm{SD}=$ Strongly disagree.

${ }^{2} \mathrm{P}$ values determined using Wilcoxon Rank Sum Test.

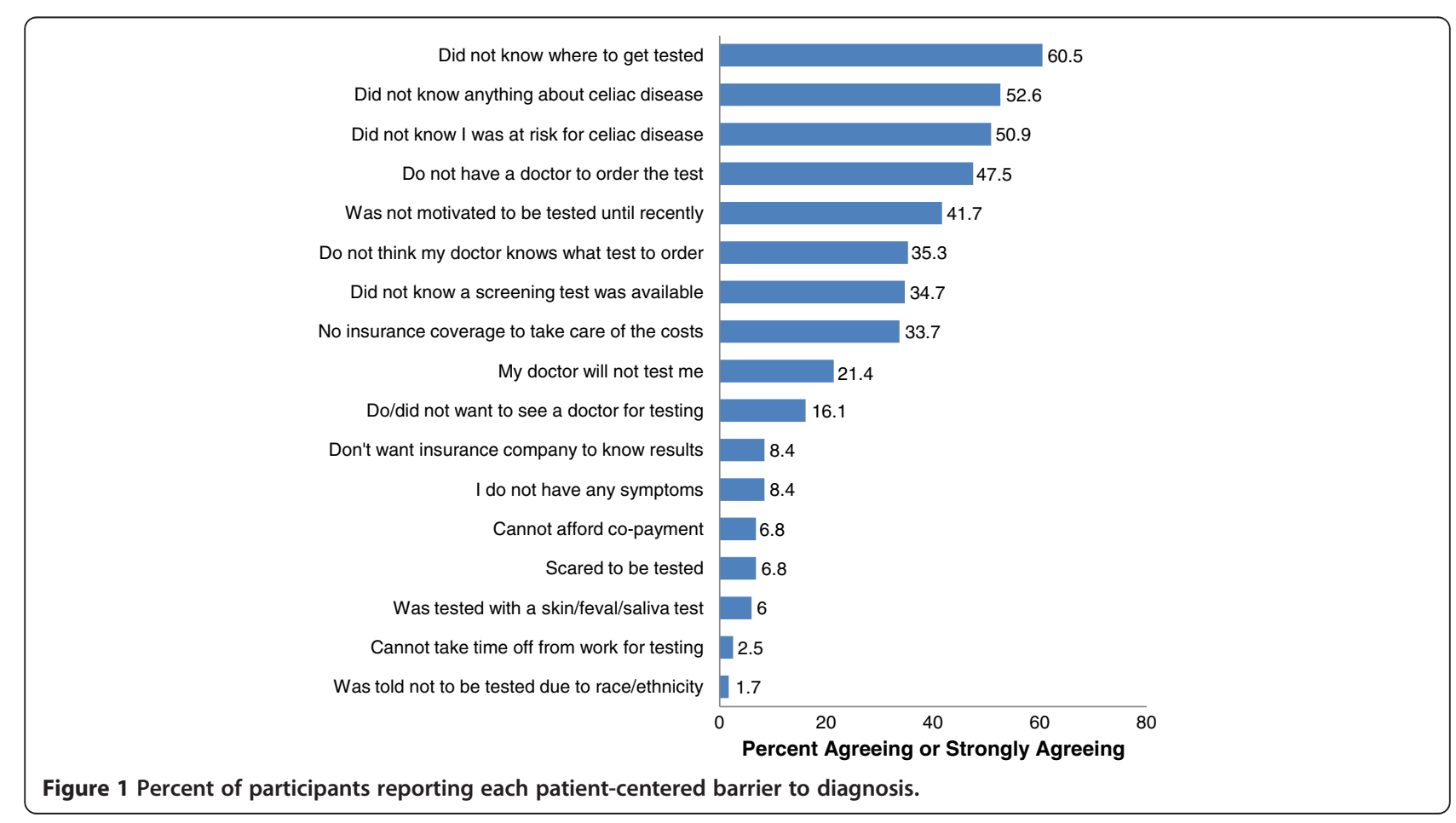




\section{Table 5 Significant barriers by demographic sub-population}

\begin{tabular}{|c|c|c|c|}
\hline Sub-population & $\mathbf{N}$ & Significant barriers & P-value \\
\hline \multicolumn{4}{|c|}{ Median age (years) } \\
\hline \multirow[t]{2}{*}{$<34.9$} & 60 & I did not know where to get tested. & 0.003 \\
\hline & & $\begin{array}{l}\text { I do not have a doctor to order the } \\
\text { test. }\end{array}$ & 0.008 \\
\hline$>34.9$ & 59 & I did not know where to get tested. & 0.012 \\
\hline \multicolumn{4}{|l|}{ Sex } \\
\hline Males & 28 & None & $>0.05$ \\
\hline \multirow[t]{2}{*}{ Females } & 91 & I did not know where to get tested. & $<0.001$ \\
\hline & & $\begin{array}{l}\text { I did not know I was at risk for celiac } \\
\text { disease. }\end{array}$ & 0.029 \\
\hline
\end{tabular}

Income (USD)

\begin{tabular}{|c|c|c|}
\hline$<\$ 25,000$ & 34 & $\begin{array}{l}\text { I do not have a doctor to order the } \\
\text { test. }\end{array}$ \\
\hline & & I did not know where to get tested. \\
\hline$\$ 25,000-\$ 50,000$ & 33 & I did not know where to get tested. \\
\hline$\$ 50,000-\$ 100,000$ & 31 & $\begin{array}{l}\text { I did not know I was at risk for celiac } \\
\text { disease. }\end{array}$ \\
\hline$>\$ 100,000$ & 16 & None \\
\hline ducation & & \\
\hline High school/GED & 11 & None \\
\hline Some college & 35 & I did not know where to get tested. \\
\hline 4 year degree & 37 & I did not know where to get tested. \\
\hline & & $\begin{array}{l}\text { I did not know I was at risk for celiac } \\
\text { disease. }\end{array}$ \\
\hline raduate degree & 35 & $\begin{array}{l}\text { I did not know I was at risk for celiac } \\
\text { disease. }\end{array}$ \\
\hline & & I did not know where to get tested. \\
\hline
\end{tabular}

Employment

\begin{tabular}{|c|c|c|}
\hline \multirow[t]{3}{*}{ Employed } & 77 & $\begin{array}{l}\text { I did not know anything about celiac } \\
\text { disease until recently. }\end{array}$ \\
\hline & & I did not know where to get tested. \\
\hline & & $\begin{array}{l}\text { I did not know I was at risk for celiac } \\
\text { disease. }\end{array}$ \\
\hline Unemployed & 42 & I did not know where to get tested. \\
\hline \multicolumn{3}{|l|}{ Ethnicity } \\
\hline $\begin{array}{l}\text { White } \\
\text { non-Hispanic }\end{array}$ & 94 & I did not know where to get tested. \\
\hline Hispanic & 16 & $\begin{array}{l}\text { I did not know I was at risk for celiac } \\
\text { disease. }\end{array}$ \\
\hline \multirow[t]{2}{*}{ Other } & 9 & $\begin{array}{l}\text { I did not know I was at risk for celiac } \\
\text { disease. }\end{array}$ \\
\hline & & $\begin{array}{l}\text { I did not know anything about celiac } \\
\text { disease until recently. }\end{array}$ \\
\hline
\end{tabular}

Includes unemployed able to work, unemployed not able to work, retirees, homemakers, students, and non-paid volunteers. those with annual incomes above $\$ 100,000$ (Table 5), $50 \%$ of this income group cited a lack of motivation as a barrier to testing $(p=0.165 ; \mathrm{N}=16)$ making lack of motivation the most common barrier cited by this group.

Not knowing where to be tested was a significant barrier across all education levels except High School/GED, which did not have any statistically significant barriers, possibly reflecting the small sample size (Table 5). The most common barrier reported by the High School/GED demographic group was, "I did not know anything about celiac disease until recently", with 8 out of 11 participants agreeing. A significant number of individuals with all other levels of education reported, "I did not know where to get tested" (Table 5). "I did not know I was a risk for celiac disease" was a significant barrier only for individuals with a four-year college or graduate degree.

Employed individuals and the unemployed faced an overlapping barrier in that both did not know where to get tested (Table 5), whereas only the employed significantly reported not knowing anything about celiac disease until recently and not knowing they were at risk for celiac disease.

Not knowing where to get tested was a significant barrier among White participants whereas not knowing they were at risk for celiac disease was a significant barrier among Hispanic participants. A significant number of individuals of other races/ethnicities reported not knowing they were at risk for celiac disease and not knowing about celiac disease until recently.

Strong correlations were found between several barriers suggesting validity of the questionnaire (Table 6). Subjects who reported "not knowing anything about celiac disease until recently" were also likely to cite that they did not know they were at risk for celiac disease. Individuals without insurance were also likely to cite the lack of a doctor to order the blood test, and individuals who did not know there was a screening test available also did not know where to get tested.

Of 119 participants, three $(2.5 \%)$ had a positive IgA tTG test (Table 7). All three identified themselves as White, non-Hispanic. In each case, levels were $>3$-fold greater than the upper limit of the laboratory's range of normal, and each also tested positive by the confirmatory IgA EMA test. Two of three serologically positive participants reported they had at least one first-degree family member with biopsy-proven celiac disease. Their qualifying risk factors, cited barriers, symptoms, and comorbid health problems were not distinguishable from those of the other 116 participants, who all had IgA tTG titers well below the laboratory cutoff values for normal.

\section{Discussion}

We report there are significant patient-centered barriers that impede serologic screening and contribute to the 
Table 6 Significant correlations between barriers

\begin{tabular}{llll}
\hline Barrier A & Barrier B & Correlation coefficient & 95\% confidence interval \\
\hline Did not know about celiac disease & Did not know I was at risk & 0.726 & 0.599 to 0.817 \\
Do not have insurance & Do not have a doctor to order test & 0.475 & 0.288 to 0.618 \\
Did not know about screening test & Did not know where to get tested & 0.364 & 0.175 to 0.531 \\
\hline
\end{tabular}

delayed detection and diagnosis of celiac disease. The diagnosis of celiac disease is delayed from 5.8 to 11 years on average after the onset of symptoms [19,20,25]. This is the case despite readily available inexpensive serologic screening tests of high sensitivity, specificity and an increased positive predictive value when applied to populations having an increased prevalence of celiac disease [31,32].

We surveyed a group of volunteers from the general population who met study inclusion criteria for symptoms, co-morbidities and/or family history placing them

Table 7 The risk factors, barriers, health problems, and subjective overall health of the participants with positive serologic studies

\begin{tabular}{|c|c|c|c|c|c|c|}
\hline & $\begin{array}{l}\text { Qualifying risk factors } \\
\text { on telephone interview }\end{array}$ & $\begin{array}{l}\text { Barriers identified on } \\
\text { survey/questionnaire }\end{array}$ & $\begin{array}{l}\text { Symptoms on } \\
\text { survey/questionnaire }\end{array}$ & $\begin{array}{l}\text { Co-morbid health problems } \\
\text { on survey/questionnaire }\end{array}$ & $\begin{array}{l}\lg A \text { tTG } \\
\text { titer }\end{array}$ & $\begin{array}{l}\text { Overall } \\
\text { health }\end{array}$ \\
\hline \multirow[t]{11}{*}{1} & Abdominal pain & \multirow{2}{*}{$\begin{array}{l}\text { Don't know where to } \\
\text { get tested }\end{array}$} & \multirow[t]{2}{*}{ Abdominal pain } & Autoimmune thyroid disease & \multirow[t]{11}{*}{29} & \multirow[t]{11}{*}{ Very good } \\
\hline & $\begin{array}{l}\text { Autoimmune thyroid } \\
\text { disease }\end{array}$ & & & Bone disease & & \\
\hline & \multirow[t]{9}{*}{ Bone disease } & \multirow{2}{*}{$\begin{array}{l}\text { Don't think my doctor } \\
\text { knows which test to order }\end{array}$} & Gas/bloating & \multirow[t]{2}{*}{ Chronic fatigue syndrome } & & \\
\hline & & & Nausea & & & \\
\hline & & My doctor won't test me & Anxiety & Depression (diagnosed) & & \\
\hline & & \multirow{6}{*}{$\begin{array}{l}\text { Don't want to eat gluten } \\
\text { to be tested }\end{array}$} & Symptoms of depression & \multirow[t]{6}{*}{ Fibromyalgia } & & \\
\hline & & & Fatigue & & & \\
\hline & & & Bone pain & & & \\
\hline & & & Skin rash & & & \\
\hline & & & Muscle pain & & & \\
\hline & & & $\begin{array}{l}\text { Recurring headaches } \\
\text { or migraines }\end{array}$ & & & \\
\hline \multirow[t]{3}{*}{2} & \multirow[t]{2}{*}{$\begin{array}{l}\text { 1st degree family member } \\
\text { with Celiac Disease }\end{array}$} & $\begin{array}{l}\text { No symptoms to cause me } \\
\text { to want to be tested }\end{array}$ & Symptoms of depression & Anemia, unknown cause & \multirow[t]{3}{*}{128} & \multirow[t]{3}{*}{ Very good } \\
\hline & & No insurance & Fatigue & Other: "chronic headaches" & & \\
\hline & Anemia & Not motivated to get tested & $\begin{array}{l}\text { Recurring headaches or } \\
\text { migraines }\end{array}$ & & & \\
\hline \multirow[t]{15}{*}{3} & \multirow{3}{*}{$\begin{array}{l}\text { 1st degree family member } \\
\text { with celiac disease }\end{array}$} & \multirow{2}{*}{$\begin{array}{l}\text { Don't have a doctor to } \\
\text { test me }\end{array}$} & Abdominal pain & Infertility & \multirow[t]{3}{*}{18} & \multirow[t]{15}{*}{ Good } \\
\hline & & & Gas/bloating & IBS & & \\
\hline & & Don't have insurance & Nausea & Iron deficiency anemia & & \\
\hline & Abdominal pain & \multirow{12}{*}{$\begin{array}{l}\text { Don't think doctor knows } \\
\text { which test to order }\end{array}$} & Diarrhea & & & \\
\hline & Diarrhea & & Anxiety & & & \\
\hline & \multirow[t]{10}{*}{ IBS } & & Symptoms of depression & & & \\
\hline & & & Fatigue & & & \\
\hline & & & $\begin{array}{l}\text { Recurring headaches } \\
\text { or Migraines }\end{array}$ & & & \\
\hline & & & Muscle pain & & & \\
\hline & & & Constipation & & & \\
\hline & & & $\begin{array}{l}\text { Poor dental enamel } \\
\text { formation }\end{array}$ & & & \\
\hline & & & Mouth sores & & & \\
\hline & & & Tingling extremities & & & \\
\hline & & & Joint pain & & & \\
\hline & & & Weight loss (unintentional) & & & \\
\hline
\end{tabular}


clinically in populations with an increased prevalence of celiac disease. Participants had a sex ratio that paralleled that found among diagnosed celiac disease patients, symptoms and co-morbidities typical of those found in diagnosed celiac disease patients and a broad range of income and education levels $[6,12,19,23]$.

We reasoned a priori that key patient-centered barriers would relate to a lack of knowledge about celiac disease and serologic testing. This proved to be the case as the most significant barriers among the participant group were, "I did not know I was at risk for celiac disease" and "I did not know where to get tested". Although our study was powered to find significant barriers that affect the entire participant group, we cautiously point out several barriers that were found in some of the demographic subgroups and may indicate worthwhile avenues for further research or outreach. Regarding access to healthcare, for example, not having a doctor was a significant barrier among those with annual incomes less than $\$ 25,000$ and those in the younger half of participants. Consistent with this, not having health insurance strongly correlated with participants not having a doctor. It remains to be seen to what extent recent changes in health care laws will increase the number of Americans with both insurance and a doctor, and if this will lead to a higher frequency of testing among individuals in those demographic groups.

Lack of knowledge among the public about celiac disease, its symptoms, and risk factors represented an important barrier to diagnosis. More than $50 \%$ of participants reported not knowing anything about celiac disease until recently or not knowing that they were at risk for celiac disease. As a result, at-risk patients seeing a doctor for their symptoms would be unlikely to question their physicians about celiac disease or request serologic testing. Interestingly, more than a third of participants did not think their doctor would know which test to order, suggesting low patient confidence in physician knowledge about celiac disease. Consistent with that, primary care doctors, who form the front line for detection of probable celiac disease, were in fact found to have limited knowledge of the symptoms, natural history, and methods of testing for celiac disease, implying that greater education of health care professionals about celiac disease would be beneficial [33]. To address both problems, the National Institute of Health launched a campaign in 2006 to increase celiac disease awareness among health-care professionals and the public [34]. In addition, the growing presence of gluten-free food products in grocery stores, gluten-free options on restaurant menus, and articles about celiac disease and non-celiac gluten sensitivity in the lay press also may help to increase public awareness and the patient-physician conversation on this topic.

A lack of motivation to get tested for celiac disease was self-reported in more than $40 \%$ of participants and was the most common barrier cited by those in the highest income group. Nonetheless, each participant possessed sufficient motivation to contact the Warren Medical Research Center for Celiac Disease after seeing our posted flyers, engage in a telephone screening process, and, if qualified, complete the study. Study completion required the time and the cost of travel to the UCSD campus, the time taken to complete a 20-30 minute questionnaire, and the donation of a blood sample for celiac serology. This level of motivation likely exceeds that in the general population.

Individuals with celiac disease present with a spectrum of intestinal and extraintestinal symptoms. Many of these symptoms are not debilitating, and patients often learn to "live with" their symptoms despite a decreased quality of life. This is consistent with $85 \%$ of the participants rating their overall health as good to excellent and may help explain a lack of motivation for testing. Although 10 participants claimed to not have symptoms at the time of the screening telephone interview, each of them reported symptoms consistent with celiac disease on our questionnaire.

Three of 119 (2.5\%) of participants enrolled in the study, or roughly $1: 40$, tested positive for IgA tTG. This is consistent with a prior study in which 1 in 56 (1.7\%) symptomatic individuals tested had positive serology, compared to $1: 133(0.7 \%)$ of the general population [6]. The fact that $2 / 33(6 \%)$ of our participants who indicated they had a first degree relative with celiac disease tested positive for IgA tTG is consistent with the reported prevalence of celiac disease in $5-10 \%$ of first-degree relatives of celiac disease probands [7,31]. The 3 serologically positive individuals in our study would be classified as presumptive celiac disease according to AGA criteria [8], since small intestinal mucosal biopsy was not included as part of this barriers research study. We do not know whether any of the participants with symptoms and negative IgA tTG values have non-celiac gluten sensitivity $[18,35,36]$.

AGA, ACG, and NIH recommendations favor active case-finding, rather than general population screening $[8,17,18]$. This strategy is more cost-effective as it increases the pretest probability and therefore the rate of positive testing, leading to fewer unnecessary procedures [9]. However, such guidelines leave the question as to whom to screen open to clinical discretion as many common symptoms and co-morbidities are associated with an increased prevalence of celiac disease. For example, a study using an active-case finding strategy to screen for celiac disease reported that $64 \%$ of survey respondents met the criteria for celiac screening [37]. This strategy will also miss many individuals with asymptomatic celiac disease and those with atypical symptoms. Notably, the case-finding strategy thus far has failed to detect and diagnose a large majority of individuals with 
active celiac disease. However, it is also controversial as to whether celiac disease is an appropriate disease for mass screening consistent with World Health Organization criteria [9]. Nonetheless, it is clear that new improved testing strategies for celiac disease appropriate for application in the general or select populations are required.

Several limitations of this study are worth noting. We powered the study to find significant barriers overall, and this limited the ability to definitively delineate some of the barriers within distinct demographic subgroups. Participants were not a random sample from high celiac disease prevalence populations. We designed the study such that participants were individuals from the general population who met criteria for being at a higher risk for celiac disease than those in the general population at large. Further, the study did not accurately reflect the ethnic populations residing in San Diego County as it included $13.4 \%$ of participants who self-identified as Hispanic, compared to the $33 \%$ of residents of San Diego County who reported as Hispanic by census [38]. Finally, we note that large prevalence studies have reported roughly equal numbers of men and women with celiac disease [6,23]. Nonetheless, women are more frequently diagnosed with celiac disease than men at a rate of roughly $3: 1$, and the population of women and men who volunteered for this study was consistent with that ratio $[12,19,29,30]$. This female predominance may reflect a greater likelihood for women to seek medical attention for their symptoms or press their physicians for celiac testing. In this study, our advertising strategy (e.g. in grocery stores) may have reached more women than men.

\section{Conclusions}

The under-detection and diagnosis of celiac disease may be partially explained by patient-centered barriers related to lack of knowledge regarding celiac disease symptoms, risk factors, and screening tests. Many individuals face barriers secondary to poor access to healthcare as well. Future public awareness campaigns, improved access to healthcare, and the development of cheaper and more accurate modes of testing have the potential to increase the rate of diagnosis of this common chronic disease.

\section{Additional files}

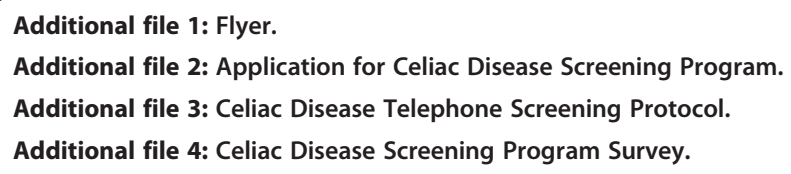

\section{Abbreviations}

ACG: American College of Gastroenterologists; AGA: American Gastroenterological Association; EMA: Endomysial antibody; HLA: Human leukocyte antigen; IgA: Immunoglobulin A; NIH: National Institute of Health; tTG: tissue transglutaminase; UCSD: University of California, San Diego.

\section{Competing interests}

The authors declare that they have no competing interests.

\section{Authors' contributions}

MFK contributed to study concept and design, data assembly, and interpretation, and drafting of the manuscript. SLM contributed to study concept and design. EMB contributed to data collection, data interpretation, and drafting of the manuscript. MCD contributed to study design and power, and data biostatistics. All authors read and approved the final manuscript.

\section{Authors' information}

Martin F. Kagnoff is Director of the Laboratory of Mucosal Immunology and the William K. Warren Medical Research Center for Celiac Disease at the University of California, San Diego, and an expert in mucosal immunology and the diagnosis, pathogenesis, and treatment of celiac disease. Shawna L. McNally is a Registered Dietician, Master of Public Health, Nutrition Research Consultant at the Harvard Center for Population and Development Studies, and expert in celiac disease nutrition. Michael C. Donahue is Professor of Biostatistics and Bioinformatics at the University of California, San Diego, and expert in clinical trial design and analysis. Erika M. Barbero completed these studies in fulfillment of an independent study project for the University of California, San Diego, School of Medicine.

\section{Acknowledgements}

This work was supported by a grant from the William K. Warren Foundation and National Institute of Health grant DK35108 to Martin F. Kagnoff. We thank K.C. Moua and P. Galindo for expert data collection and study coordination. The funding body had no role in this study or its publication.

\section{Author details}

1Department of Medicine, Division of Gastroenterology, University of California San Diego, 9500 Gilman Drive, La Jolla, CA 92093 MC 0623D, USA. ${ }^{2}$ Current Address: Nutrition Research Consultant, Harvard Center for Population and Development Studies, Providence, RI, USA. ${ }^{3}$ Department of Family and Preventive Medicine, Division of Biostatistics and Bioinformatics, University of California San Diego, La Jolla, CA, USA. ${ }^{4}$ Department of Pediatrics, Division of Gastroenterology, University of California San Diego, La Jolla, CA, USA.

Received: 24 November 2013 Accepted: 28 February 2014

Published: 5 March 2014

\section{References}

1. Mustalahti K, Catassi C, Reunanen A, Fabiani E, Heier M, McMillan S, Murray L, Metzger MH, Gasparin M, Bravi E, Mäki M, Coeliac EU Cluster, Project Epidemiology: The prevalence of celiac disease in Europe: results of a centralized, international mass screening project. Ann Med 2010, 42:587-595.

2. Alarida K, Harown J, Ahmaida A, Marinelli L, Venturini C, Kodermaz G, Tozzoli R, Mandolesi A, Bearzi I, Catassi C: Coeliac disease in Libyan children: a screening study based on the rapid determination of anti-transglutaminase antibodies. Dig Liver Dis 2011, 43:688-691.

3. Cummins AG, Roberts-Thomson IC: Prevalence of celiac disease in the Asia-Pacific region. J Gastroenterol Hepatol 2009, 24:1347-1351.

4. Kagnoff MF: Celiac disease: pathogenesis of a model immunogenetic disease. J Clin Invest 2007, 117:41-49.

5. Reilly NR, Green PH: Epidemiology and clinical presentations of celiac disease. Semin Immunopathol 2012, 34:473-478.

6. Fasano A, Berti I, Gerarduzzi T, Not T, Colletti RB, Drago S, Elitsur Y, Green PH, Guandalini S, Hill ID, Pietzak M, Ventura A, Thorpe M, Kryszak D, Fornaroli F, Wasserman SS, Murray JA, Horvath K: Prevalence of celiac disease in at-risk and not-at-risk groups in the United States. Arch Intern Med 2003, 163:286-292.

7. Book L, Zone JJ, Neuhausen SL: Prevalence of celiac disease among relatives of sib pairs with celiac disease in U.S. families. Am J Gastroenterol 2003, 98:377-381.

8. Rostom A, Murray JA, Kagnoff MF: American Gastroenterological Association (AGA) Institute technical review on the diagnosis and management of celiac disease. Gastroenterology 2006, 131:1981-2002. 
9. Aggarwal S, Lebwohl B, Green PH: Screening for celiac disease in average-risk and high-risk populations. Therap Adv Gastroenterol 2012, 5:37-47.

10. Rivera E, Assiri A, Guandalini S: Celiac disease. Oral Dis 2013, 19:635-641.

11. Pellecchia MT, Scalia R, Filla A, De Michele G, Ciacci C, Barone P: Idiopathic cerebellar ataxia associated with celiac disease: lack of distinctive neurological features. J Neurol Neurosurg Psychiatry 1999, 66:32-35.

12. Cranney A, Zarkadas M, Graham ID, Butzner JD, Rashid M, Warren R, Molloy M, Case S, Burrows V, Switzer C: The Canadian celiac health survey. Dig Dis Sci 2007, 52:1087-1095.

13. Cash BD, Rubenstein JH, Young PE, Gentry A, Nojkov B, Lee D, Andrews AH, Dobhan R, Chey WD: The prevalence of celiac disease among patients with nonconstipated irritable bowel syndrome is similar to controls. Gastroenterology 2011, 141:1187-1193.

14. Zintzaras E, Germenis AE: Performance of antibodies against tissue transglutaminase for the diagnosis of celiac disease: meta-analysis. Clin Vaccine Immunol 2006, 13:187-192.

15. Institute AGA: AGA Institute medical position statement on the diagnosis and management of celiac disease. Gastroenterology 2006, 131:1977-1980.

16. Husby S, Koletzko S, Korponay-Szabó IR, Mearin ML, Phillips A, Shamir R, Troncone R, Giersiepen K, Branski D, Catassi C, Lelgeman M, Mäki M, Ribes-Koninckx C, Ventura A, Zimmer KP, ESPGHAN Working Group on Coeliac Disease Diagnosis; ESPGHAN Gastroenterology Committee; European Society for Pediatric Gastroenterology, Hepatology, and Nutrition: European society for pediatric gastroenterology, Hepatology, and Nutrition guidelines for the diagnosis of coeliac disease. J Pediatr Gastroenterol Nutr 2012, 54:136-160.

17. Rubio-Tapia A, Hill ID, Kelly CP, Calderwood AH, Murray JA, American College of Gastroenterology: ACG clinical guidelines: diagnosis and management of celiac disease. Am J Gastroenterol 2013, 108:656-676.

18. Elson CO, Ballew M, Barnard JA, Bernstein SJ, Check IJ, Cohen MB, Fazio S, Johanson JF, Lindor NM, Montgomery E, Richardson LH, Rogers D, Vijan S: National institutes of health consensus development conference statement on celiac disease consensus. In Proceedings of the NIH Consensus Conference on Celiac Disease 28-30 June 2004; Gastroenterology 2005, 128(suppl 1):S1-S9.

19. Green PHR, Stavropoulos SN, Panagi SG, Goldstein SL, McMahon DJ, Absan $\mathrm{H}$, Neugut Al: Characteristics of adult celiac disease in the USA: results of a national survey. Am J Gastroenterol 2001, 96:126-131.

20. Norstrom F, Lindholm L, Sandstrom O, Nordyke K, Ivarsson A: Delay to celiac disease diagnosis and its implications for health-related quality of life. BMC Gastroenterol 2011, 11:118.

21. Rubio-Tapia A, Rahm MW, See JA, Lahr BD, Wu TT, Murray JA: Mucosal recovery and mortality in adults with celiac disease after treatment with a gluten-free diet. Am J Gastroenterol 2010, 105:1412-1420.

22. Lohi S, Maki M, Rissanen H, Knekt P, Reunanen A, Kaukinen K: Prognosis of unrecognized coeliac disease as regards mortality: a population-based cohort study. Ann Med 2009, 41:508-515.

23. Rubio-Tapia A, Kyle RA, Kaplan EL, Johnson DR, Page W, Erdtmann F, Brantner TL, Kim WR, Phelps TK, Lahr BD, Zinsmeister AR, Melton J, Murray JA: Increased prevalence and mortality in undiagnosed celiac disease. Gastroenterology 2009, 137:88-93.

24. Rubio-Tapia A, Ludvigsson JF, Brantner TL, Murray JA, Everhart JE: The prevalence of celiac disease in the United States. Am J Gastroenterol 2012, 107:1538-1544.

25. Lo W, Sano K, Lebwohl B, Diamond B, Green PH: Changing presentation of adult celiac disease. Dig Dis Sci 2003, 48:395-398.

26. Metzger MH, Heier M, Maki M, Bravi E, Schneider A, Lowel H, Illig T, Schuppan D, Wichmann HE: Mortality excess in individuals with elevated IgA anti-transglutaminase antibodies: the KORA/MONICA Augsburg cohort study 1989-1998. Eur J Epidemiol 2006, 21:359-365.

27. Dickey W, McConnell JB: How many hospital visits does it take before celiac sprue is diagnosed? J Clin Gastroenterol 1996, 23:21-23.

28. Davison AC, Hinkley DV: Bootstrap Methods and their Application. Cambridge, UK: Cambridge University Press; 1997.

29. Ciacci C, Cirillo M, Sollazzo R, Savino G, Sabbatini F, Mazzacca G: Gender and clinical presentation in adult celiac disease. Scand J Gastroenterol 1995, 30:1077-1081.

30. Green PH, Cellier C: Celiac disease. N Engl J Med 2007, 357:1731-1743.

31. Rostom A, Dube C, Cranney A, Saloojee N, Sy R, Garritty C, Sampson M, Zhang L, Yazdi F, Mamaladze V, Pan I, MacNeil J, Mack D, Patel D, Moher D:
The diagnostic accuracy of serologic tests for celiac disease: a systematic review. Gastroenterology 2005, 128(Suppl 1):S38-S46.

32. Leffler DA, Schuppan D: Update on serologic testing in celiac disease. Am J Gastroenterol 2010, 105:2520-2524.

33. Zipser RD, Farid M, Baisch D, Patel B, Patel D: Physician awareness of celiac disease: a need for further education. J Gen Intern Med 2005, 20:644-646.

34. Celiac Disease Awareness Campaign. http://celiac.nih.gov.

35. Lundin KE, Alaedini A: Non-celiac gluten sensitivity. Gastrointest EndosC Clin N Am 2012, 22:723-734.

36. Sapone A, Bai JC, Ciacci C, Dolinsek J, Green PH, Hadjivassiliou M, Kaukinen K, Rostami K, Sanders DS, Schumann M, Ullrich R, Villalta D, Volta U, Catassi C, Fasano A: Spectrum of gluten-related disorders: consensus on new nomenclature and classification. BMC Med 2012, 10:13.

37. Catassi C, Kryszak D, Louis-Jacques O, Duerksen DR, Hill I, Crowe SE, Brown AR, Procaccini NJ, Wonderly BA, Hartley P, Moreci J, Bennett N, Horvath K, Burk M, Fasano A: Detection of Celiac disease in primary care: a multicenter case-finding study in North America. Am J Gastroenterol 2007, 102:1454-1460.

38. U.S. Census Bureau: State and County QuickFacts. http://quickfacts.census. gov/qfd/states/06/06073.htm

doi:10.1186/1471-230X-14-42

Cite this article as: Barbero et al:: Barriers impeding serologic screening for celiac disease in clinically high-prevalence populations. BMC Gastroenterology 2014 14:42.

\section{Submit your next manuscript to BioMed Central and take full advantage of:}

- Convenient online submission

- Thorough peer review

- No space constraints or color figure charges

- Immediate publication on acceptance

- Inclusion in PubMed, CAS, Scopus and Google Scholar

- Research which is freely available for redistribution

Submit your manuscript at www.biomedcentral.com/submit
C) Biomed Central 